\title{
Chitosan Oligomers and Related Nanoparticles as Environmentally Friendly Wood Preservatives
}

Laya Khademibami,* Dragica Jeremic, Rubin Shmulsky, and H. Michael Barnes

\begin{abstract}
The efficacy of chitosan oligomers and related nanoparticles as environmentally friendly wood protection agents was evaluated in this study. Commercially sourced low-molecular weight chitosan was depolymerized using sodium nitrite. Evaluation of depolymerized chitosan to the nano level by thin layer chromatography confirmed acceptable results for obtaining a degree of polymerization of four. Then, oligomers were modified to form quaternized chitosan oligomers. Both quaternized and non-quaternized oligomers were mixed with tripolyphosphate (TPP) to form nano-chitosan-TPP particles via an ionic gelation method. Southern pine wood samples were treated with different chitosan-based solutions and suspensions under a vacuum impregnation process. The mass and volume of the treated samples were calculated before and after treatments to evaluate bulking. The mass loss after leaching of the treated wood samples was calculated. The mass and volume gain results indicated that quaternized nano-chitosan-TPP treated samples had more mass and volume gain after treatment in comparison with non-quaternized nano-chitosan-TPP-treated and control samples. The mass loss results revealed that mass loss increased in quaternized nano-chitosan-TPP particles. Although quaternized nano-chitosan particles were positively charged, they could not fix to the cell walls and became leached out. Therefore, these nanoparticles can likely be used as wood preservatives in non-leaching applications.
\end{abstract}

Keywords: Nano-chitosan particles; Leaching; Bulking; Southern yellow pine; Wood preservatives

Contact information: Department of Sustainable Bioproducts, Mississippi State University, Box 9820 , Starkville, MS 39762, USA; *Corresponding author: Lk475@msstate.edu

\section{INTRODUCTION}

For decades, wood scientists have been developing technologies and improving the properties of wood to increase its sustainability. Wood preservation and wood modification are solutions for increasing wood durability. Markets for chemically modified wood and heat-treated modified wood are growing. Thus, there is an ongoing need to improve wood preservation technology. Several factors are involved in choosing a suitable preservative, which include a long-term protection, stability, potential effects on wood strength, cost, and safety of the treated wood for human and environmental exposure (Ozdemir et al. 2014). Currently, the use of widely accepted preservatives plays a vital role in the wood industry. Due to environmental concerns and constraints on the use of various current heavy metal preservatives for humans and the environment, there is a new trend in wood preservation to explore more environmentally benign chemicals (Treu et al. 2009). Therefore, developing and using wood preservatives that are safe for humans and the environment that reduce hazardous wastes are vital needs.

Recently, chitosan has been gaining attention due to its non-toxic nature, antimicrobial activity, biodegradability, and biocompatible abilities (Xu et al. 2010; Kumar et al. 2017; Ikono et al. 2019). Chitosan has a chemical structure similar to cellulose and is the next most widely available natural polymer after the main components of wood 
(Kumar 2000). Chitosan, as a natural polymer, is derived from chitin, which is a biopolymer and polysaccharide component of crustacean shells such as shrimps, crabs, and lobsters. Chitosan is generally water-soluble under acidic conditions, while chitin is insoluble in water (Eikenes et al. 2005). Antifungal activity of chitosan against wooddecaying fungi and forest pathogens has been previously reported (Chittenden et al. 2003; Alfredsen et al. 2004; Eikenes et al. 2005). Amino groups in chitosan structure exhibit antimicrobial activities (Seong et al. 1999; Junior 2016). Chitosan has varying average molecular weights. Different molecular weights of chitosan have been studied for wood treatment (Larnoy et al. 2006a).

Regardless of different molecular weights (high and low) of chitosan, the penetrability of chitosan into wood cells is associated with concentration. Chitosan with lower concentrations (and their associated lower viscosities) exhibits a greater fixation as well as increased penetration into wood cell walls (Larnoy et al. 2006b). Higher concentrations $(>4 \%)$ of chitosan have better performance for suitable antifungal activity (Hussain et al. 2012). Thus, a nano-polymer form of chitosan should be used to maximize its bonding to wood and to optimize antimicrobial activities. Chitosan can be easily refined toward the nanoscale by chemical processing to form nano-sized particles. This paper is the first of two evaluating the efficacy of nano-chitosan as an environmentally friendly wood preservative agent in indoor and outdoor applications. This paper covers the preparation of nano-chitosan-tripolyphosphate (TPP) particles, bulking of treated samples, and the leachability of the preservative system. A second paper will discuss bio-efficacy.

\section{EXPERIMENTAL}

\section{Materials}

The methodology of this study focused on two main parts, the preparation of nanochitosan-TPP particles as wood preservatives and the treatment of wood samples with nano-chitosan oligomers and N,N,N-trimethylchitosan (TMC) oligomers alone or in combination with TPP.

\section{Preparation of Nano-chitosan-TPP Wood Preservatives}

Depolymerization of chitosan to oligomers

Commercially available low-molecular weight (LMW) chitosan (50 kDa to 190 $\mathrm{kDa}$ ) with a degree of deacetylation greater than $75 \%$ was used (Sigma-Aldrich, St. Louis, MO, USA). Chitosan was depolymerized by nitrous acid into oligomers with a degree of polymerization ( $\mathrm{DP}=4$ ) according to the method described by Hussain et al. (2012). Briefly, $40 \mathrm{~g}$ of chitosan was stirred into $0.1 \mathrm{M}$ aqueous HCL $(800 \mathrm{~mL})$ and was heated to $50{ }^{\circ} \mathrm{C}$ for $1 \mathrm{~h}$. Then, an applicable amount of $\mathrm{NaNO}_{2}$ was dissolved in $32 \mathrm{~mL}$ of water ( $16.56 \mathrm{~g}$ obtaining $40 \mathrm{~g}$ of $\mathrm{DP}=4$ ). The $\mathrm{NaNO}_{2}$ was added dropwise to the chitosan solution and stirred for $30 \mathrm{~min}$ by lowering the viscosity of the mixture. The reaction mixture was stirred at $50{ }^{\circ} \mathrm{C}$ for $5 \mathrm{~h}$. Then, $1 \mathrm{M} \mathrm{NaOH}$ was added to neutralize the solution ( $\mathrm{pH} 7$ to $\mathrm{pH}$ 7.5). The solution was filtered through Teflon filter paper. The filtrate was participated by methanol 1/1 (v/v). Finally, the supernatant of methanol was precipitated with acetone 1/1 $(\mathrm{v} / \mathrm{v})$. Chitosan oligomers were previously obtained by precipitation in acetone after depolymerization by nitrous acid (Furusaki et al. 1995; Cha et al. 2000). Therefore, the precipitate of acetone in current study was understood to consist mainly of chitosan oligomers $(\mathrm{DP}=4)$. 
Analysis of chitosan oligomers by thin layer chromatography (TLC)

Chitosan oligomers were qualitatively analyzed by thin layer chromatography (TLC) using a silica gel plate (Merck 60. GF-254; Sigma-Aldrich, St. Louis, MO, USA) and compared to the standard chitotetraose (tetramer, DP =4). The standard chitotetraose, $4 \mathrm{HCl}$ was purchased from Carbosynth, Co. (Compton, England). Both chitosan oligomers and standard were dissolved in 50\% methanol and loaded on TLC plate with three different volumes $(1 \mu \mathrm{L}, 2 \mu \mathrm{L}$, and $3 \mu \mathrm{L})$. The plate was placed into the solvent system of npropanol-30\% ammonia water $(2: 1 \mathrm{v} / \mathrm{v})$ for $24 \mathrm{~h}$. Finally, spots were visualized by spraying $\left(0.1 \%\right.$ ninhydrin into n-butanol-saturated water) and then baked in an oven at $110{ }^{\circ} \mathrm{C}$ for 10 min according to the method described by Choi et al. (2004).

\section{Quaternization of chitosan oligomers (Preparation of $N, N, N$-trimethylchitosan)}

Chitosan oligomers from the depolymerization process were dissolved in $1 \% \mathrm{w} / \mathrm{w}$ aqueous acetic acid solution according to the procedure described by Bordenave et al. (2008). This process was performed in two separate steps. In the first step, formaldehyde (3 mol formaldehyde per mol of chitosan-free amine groups) was added to chitosan oligomers. Then, the solution was stirred at $500 \mathrm{rpm}$ at room temperature for $30 \mathrm{~min}$ before adding $\mathrm{NaBH}_{4}$ (1.5 mol of $\mathrm{NaBH}_{4}$ per mol of formaldehyde), and then the solution was stirred for $1 \mathrm{~h}$. The $\mathrm{pH}$ was adjusted to 10 using $1 \mathrm{M} \mathrm{NaOH}$. The unreacted products were then removed by soaking the dialysis tubes (Biotech CE Dialysis Tubing, New Brunswick, NJ, USA) $0.1 \mathrm{kDa}$ to $0.5 \mathrm{kDa}$ molecular weight cut-off (MWCO) in water, and then unreacted products were removed by soaking an ethanol/diethyl ether solution (80/20 v/v) for $48 \mathrm{~h}$. In the second step, formed $\mathrm{N}$-methyl chitosan was dispersed in N-methyl-2pyrrolidinone with $\mathrm{Na}_{2} \mathrm{SO}_{4}(0.1 \mathrm{M})$ at $60{ }^{\circ} \mathrm{C}$ and later stirred at $1200 \mathrm{rpm}$ for $1 \mathrm{~h}$. Approximately $15 \%$ w/w aqueous solution of $\mathrm{NaOH}$ containing $\left(\mathrm{CH}_{3} \mathrm{O}\right)_{2} \mathrm{SO}_{2}(1.5 \mathrm{~mol}$ of dimethyl sulfate per mole of free amine groups of the extracted and dried N-methyl chitosan) was added. The mixture was stirred at $500 \mathrm{rpm}$ at $60{ }^{\circ} \mathrm{C}$ for $6 \mathrm{~h}$. Finally, formed $\mathrm{N}, \mathrm{N}, \mathrm{N}$-trimethylchitosan was precipitated using acetone, washed with acetone, and dried under vacuum at room temperature above $\mathrm{P}_{2} \mathrm{O}_{5}$. The $\mathrm{N}, \mathrm{N}, \mathrm{N}$-trimethylchitosan (quaternized chitosan oligomers or TMC) was considered a final product for this step.

\section{Preparation of nano-chitosan-TPP particles}

Nano-chitosan-TPP particles for non-quaternized oligomers and TMC samples were prepared according to the procedure described by Huang et al (2009). Briefly, chitosan oligomers were dissolved in $2 \%$ acetic acid and stirred for $30 \mathrm{~min}$. Then, $85 \%$ sodium tripolyphosphate (TPP) (Acros Organics, Geel, Belgium) was dissolved in doubledistilled water. In the meantime, non-quaternized oligomers and TMC solutions were stirred at room temperature; then TPP solution was added dropwise at a ratio of 2:5 (TPP: chitosan, 4.8:12, w/w) for $2 \mathrm{~h}$. This mass ratio was determined to maximize the number of nanoparticles (Huang et al. 2009). After stirring for $2 \mathrm{~h}$, the solution became opalescent. It was then aliquoted into 50-mL centrifuge bottles and centrifuged at $3000 \mathrm{rpm}$ for $10 \mathrm{~min}$. The precipitated nanoparticles were rinsed with distilled water and air-dried to increase concentration. The final concentrations for chitosan and TPP were $12 \%$ and $4.8 \%$, respectively. 
Analysis of nano-chitosan oligomers, quaternized nano-chitosan oligomers, and nano chitosan-TPP particles

Nano-chitosan oligomers, quaternized nano-chitosan oligomers, and nano chitosanTPP particles were characterized by Fourier transform infrared spectroscopy (FTIR) (PerkinElmer Spectrum Two Spectrometer: PerkinElmer, Waltham, MA, USA). The FTIR analysis was performed between $450 \mathrm{~cm}^{-1}$ to $4000 \mathrm{~cm}^{-1}$ using the attenuated total reflectance spectroscopy method (ATR-FTIR). The samples were placed on the ATR crystal prism and 16 scans were attained at $2 \mathrm{~cm}^{-1}$ resolution.

\section{Preparation of Wood Samples and Impregnation of Wood Samples with Nano-chitosan-TPP Particles}

A piece of defect-free southern yellow pine (Pinus spp.) sapwood (Sustainable Bioproducts Department, Starkville, MS, USA) with a density of $0.31 \mathrm{~g} / \mathrm{cm}^{3}$ (oven-dry mass and volume) was cut to make samples with dimensions of $1.4 \mathrm{~cm} \times 1.4 \mathrm{~cm} \times 1.4 \mathrm{~cm}$ $(1 \times \mathrm{r} \times \mathrm{t})$ from two adjacent (end matched) wood sticks. Samples were dried to a constant weight at $50{ }^{\circ} \mathrm{C}$. Dry dimensions and mass of all wood samples were measured using a digital caliper and balance that was accurate to $0.1 \mathrm{mg}$ (Precision Balance ME103TE/00; Mettler Toledo, Columbus, OH, USA).

Wood samples were vacuum (> $28 \mathrm{mmHg}$ ) impregnated with an $12 \%$ aqueous solution of nano-chitosan particles for $20 \mathrm{~min}$. To increase reactivity of wood and promote binding of nano-chitosan-TPP particles to wood, pine wood samples were enzymatically and chemically modified. Chemical modification of wood was performed by acetic acid, and enzymatic modification was obtained through a laccase-mediator system (LMS). Laccase is a copper-containing oxidase enzyme that is found in plants, fungi, and microorganisms. In the presence of the mediator, rates of reactions of laccase can be enhanced. Hydroquinone (HQ), 1-hydroxybenzotriazole (HBT), and 2,2'-azino-bis, 3ethylbenzothiazoline-6-sulphonic acid (ABTS) are three common mediators, which have been used with laccase as substrates (Morozova et al. 2007). To determine the best mediator for laccase in this research, compression strength testing of wood samples treated with LMS was performed. Undried samples were performed by a compression instrument designed and manufactured at Mississippi State's Forest Products Laboratory. The results of compression strength testing indicated that HQ was the best among the three mediators that were considered (Table 1).

Overall, 17 treatments with 35 replicates per treatment group were used in this study. The treatments, including controls and nano-chitosan treatments, are listed and described in Table 2. The control treatments were a positive control without TPP and negative control with only $1 \%$ acetic acid.

Table 1. Compression Strength Results to Determine the Best Mediator for LMS

\begin{tabular}{|l|l|}
\hline Mediator & Compression LSmean $\left(\mathrm{g} / \mathrm{mm}^{2}\right)$ \\
\hline HQ & 171.63 \\
\hline HBT & 129.19 \\
\hline ABTS & 151.16 \\
\hline
\end{tabular}


Table 2. Wood Treatments

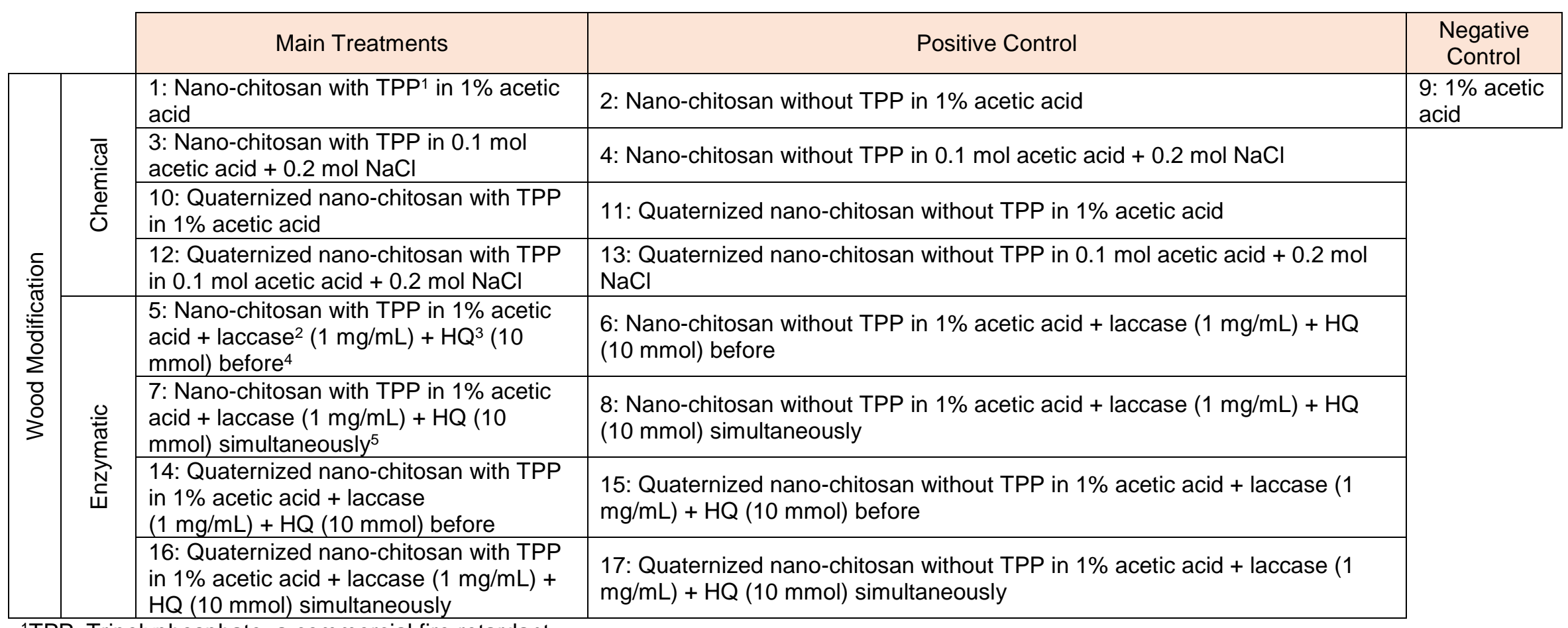

${ }^{1}$ TPP: Tripolyphosphate, a commercial fire retardant.

Laccase: copper-containing oxidase enzymes found in many plants, fungi, and microorganisms.

${ }^{3} \mathrm{HQ}$ : Hydroquinone, mediator of laccase modification. A mediator is used to oxidize and subsequently increase reactivity of wood and promote binding of chitosan to wood.

${ }^{4}$ Before preservative treatment: first, treat wood with laccase and hydroquinone. Then, treat wood with nano-chitosan particles.

${ }^{5}$ Simultaneously: Treat wood with laccase + hydroquinone and nano-chitosan particles at the same time. 


\section{Bulking and Retention}

Retention was calculated using the value for mass gain (Eq. 1),

$$
\text { Mass gain }=\frac{m_{2}-m_{1}}{m_{1}} \times 100(\%)
$$

where $m_{2}$ is the dry mass after treatment ( $\mathrm{g}$ ) and $m_{1}$ is the dry mass (g) before treatment. Bulking coefficient is based on volume gain due to treatment (Eq. 2),

$$
\text { Volume gain }=\frac{V_{2}-V_{1}}{V_{1}} \times 100(\%)
$$

where $V_{2}$ is the dry volume after treatment $\left(\mathrm{mm}^{3}\right)$ and $V_{1}$ is the dry volume $\left(\mathrm{mm}^{3}\right)$ before treatment.

\section{Leaching}

To evaluate the efficacy of nano-chitosan for long-term protection, leaching resistance of wood treated with nano-chitosan-TPP particles was evaluated according to AWPA E11-16 (2016). The samples were submerged in deionized water for two weeks, and the water was changed at predetermined standard time intervals during that time. The results of leaching were calculated as a percentage of mass loss according to the following equation,

$$
\text { Mass loss }=\frac{m_{1}-m_{2}}{m_{1}} \times 100(\%)
$$

where $m_{1}$ is the dry mass $(\mathrm{g})$ before leaching and $m_{2}$ is the dry mass (g) after leaching.

\section{Statistical Analysis}

The experimental design was a completely randomized design, and data for the bulking and leaching tests were analyzed using one-way analysis of variance (ANOVA). The procedure for linear mixed models (PROC GLIMMIX) of SAS 9.4@ (SAS Institute Inc, Cary, NC),

$$
Y_{\mathrm{ij}}=\mu+T_{\mathrm{i}}+E_{\mathrm{ij}}
$$

where $\mu$ is the population mean, $N j$ is the effect of nano-chitosan-TPP treatments ( $T=1$ to $17)$, and $E_{\mathrm{ij}}$ is the residual error.

Data for mass and volume gain as well as mass loss data were further tested by contrast analysis using the MIXED procedure of SAS 9.4@. The effects of quaternized nano-chitosan-TPP treatments $v s$. non-quaternized nano-chitosan-TPP treatments, control $v s$. quaternized nano-chitosan-TPP treatments, control $v s$. non-quaternized nano-chitosan treatments, nano-chitosan-TPP particles vs. nano-chitosan without TPP particles, and nanochitosan-TPP particles $v s$. controls were also tested.

\section{RESULTS AND DISCUSSION}

\section{Characterization of Chitosan Oligomers by TLC}

Figure 1 demonstrates that ninhydrin reacted with free amine groups and produced a deep purple color. This result was confirmed by quantitative determination of free amino groups in chitosan using a method introduced by Curotto and Aros (1993). 
Figure 1 also indicates that chitosan oligomers comprised a range of degrees of polymerization $\left(\mathrm{DP}_{\mathrm{n}}\right)$ that started from 4 when compared to standard chitotetraose $\left(\mathrm{DP}_{\mathrm{n}}\right.$ : 4). Chitotetraose was a standard with $\mathrm{DP}_{\mathrm{n}}$ of 4 with 4 amine groups (right part of TLC plate in Fig. 1). The desired $\mathrm{DP}_{\mathrm{n}}$ could be achieved with an applicable amount of sodium nitrite.

The TLC analysis revealed that chitosan with a $\mathrm{DP}_{\mathrm{n}}$ of 4 was formed through the depolymerization process of LMW chitosan. Cabrera and Cutsem (2005) prepared chitosan oligomers with a degree of polymerization greater than six using acid and enzymatic processes. They used TLC plating to separate methanol soluble chitooligomers. They reported that chitooligomers with degree of polymerization greater than six cannot be separated with this method and the TLC plate only shows chitooligosaccharide with degrees of polymerization less than six.

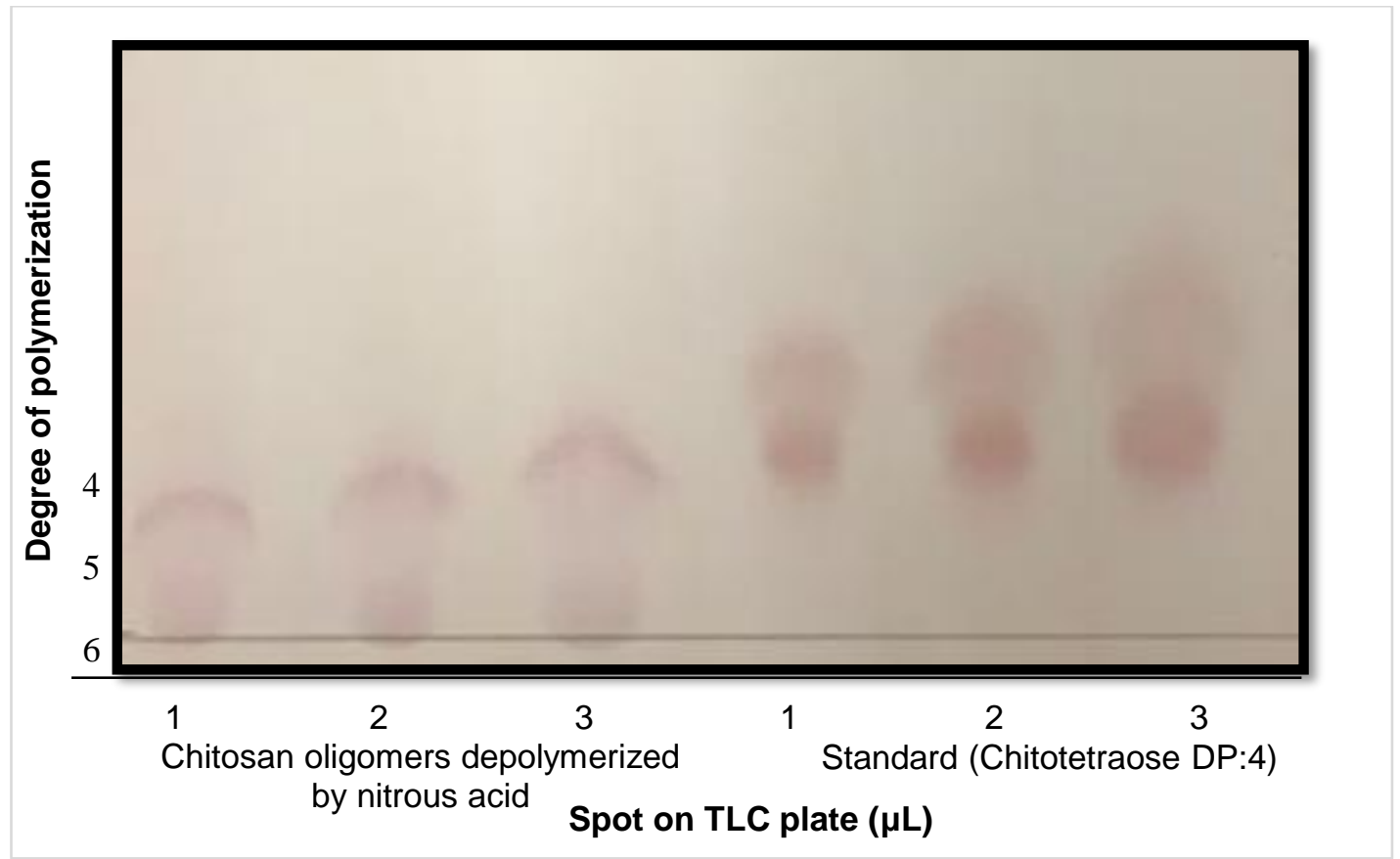

Fig. 1. Thin layer chromatography analysis of chitosan oligomers and chitotetraose

Characterization of Nano-chitosan Oligomers, Quaternized Nano-chitosan Oligomers, and Nano-chitosan-TPP Particles by FTIR

Characterization of nano-chitosan oligomers

The FTIR of chitosan oligomers was obtained after depolymerization of LMW chitosan. These oligomers were then compared to LMW chitosan (Fig. 2). This result indicated that there was a strong chemical structure resemblance between chitosan oligomers and LMW chitosan. However, molecular weight, DP, and degree of acetylation were different between chitosan oligomers and LMW chitosan. In chitosan oligomers, there was a decrease in peaks $1030 \mathrm{~cm}^{-1}$ to $990 \mathrm{~cm}^{-1}$ attributed to the loss of C-O-C bonds. This indicated that there was a breakdown of chitosan chains. Compared to LMW chitosan, a $1700 \mathrm{~cm}^{-1}$ peak subjected to the carbonyl band of an aldehyde group had more intensity in chitosan oligomers, which led to more terminal aldehyde groups in chitosan oligomers. 


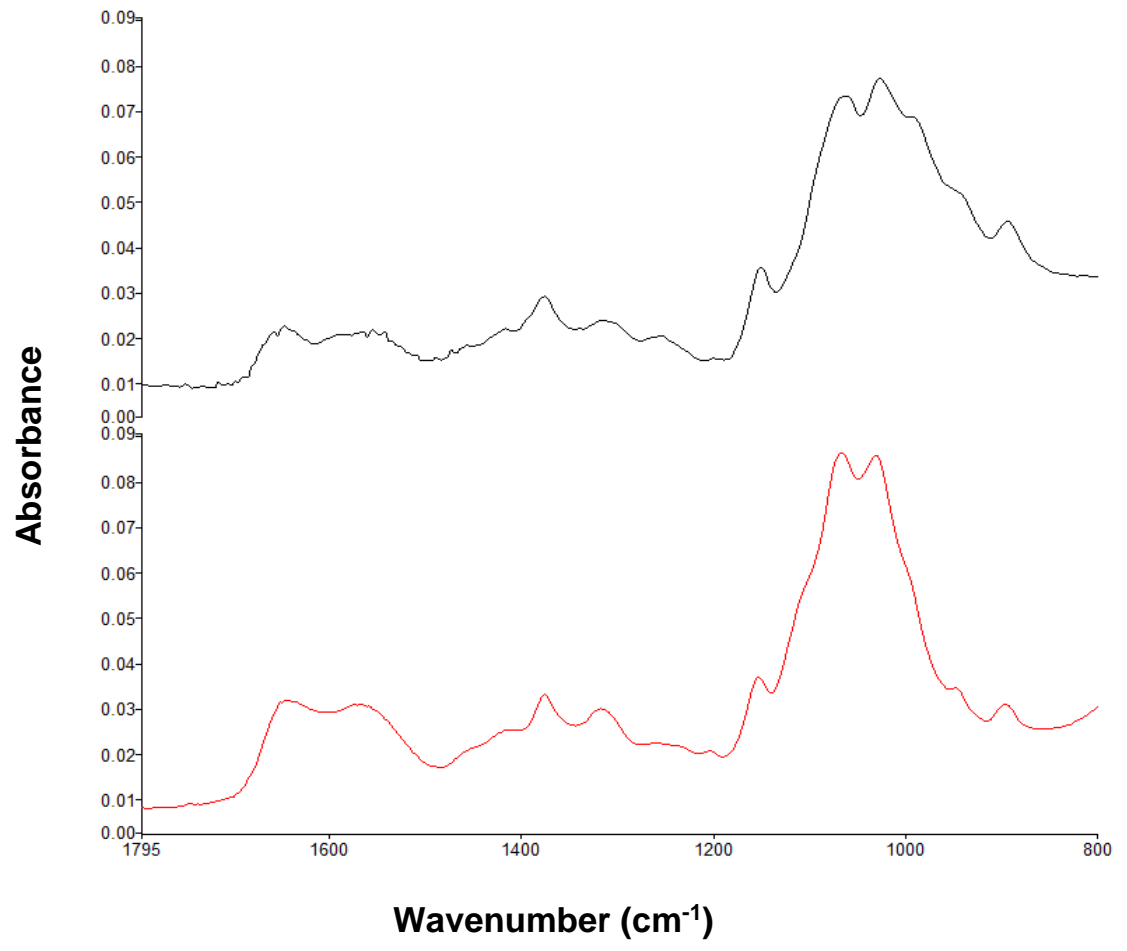

Fig. 2. FTIR of chitosan LMW (black) and nano-chitosan oligomers (red)

\section{Characterization of quaternized nano-chitosan oligomers}

The quaternization process was performed after depolymerization and after N,N,Ntrimethyl chitosan (TMC) was obtained from chitosan oligomers. Quaternized nanochitosan is a cationic polyelectrolyte, non-toxic, biocompatible polymer. It is a watersoluble molecule that can be used for nanoparticle production (Xu et al. 2003). In Fig. 3, the peak at $1492 \mathrm{~cm}^{-1}$ was asymmetrical to a stretch of $\mathrm{C}-\mathrm{H}$ in methyl groups that was produced in quaternized nano-chitosan oligomers. This peak was new and confirmed that quaternized nano-chitosan oligomers had methyl groups in their structures. Xu et al. (2010) used methyl iodide for methylation of low-molecular weight of chitosan. After FTIR was completed, it was found that there was an asymmetrical stretching of the $\mathrm{C}-\mathrm{H}$ bond in the methyl group at peak $1490 \mathrm{~cm}^{-1}$ in TMC. Xu et al. (2010) also reported that this peak was because of the highly methylated quaternary of chitosan. The FTIR results of quaternized nano-chitosan oligomers (TMCs) are shown in Fig. 3. In Fig. 3, spectra of quaternized nano-chitosan oligomers were compared to the spectra of non-quaternized nano-chitosan oligomers. Several structural differences were found between these two spectra, which indicated that the derivative from chitosan oligomers exhibited several chemical structural changes. In agreement with the current study, quaternization of high molecular weight (HMW) chitosan was successfully performed by methylation of hydroxyl and amino groups (Bordenave et al. 2008). However, asymmetrical stretching of $\mathrm{C}-\mathrm{H}$ bond in the methyl group was also reported at the $1475 \mathrm{~cm}^{-1}$ peak in derivative chitosan (TMC) from HMW chitosan (De Britto et al. 2012; Mansur et al. 2013). In addition, the peak at 1590 $\mathrm{cm}^{-1}$ linked to deformation of $\mathrm{N}-\mathrm{H}$ in amino groups, which was also previously reported by De Britto et al. (2012). 


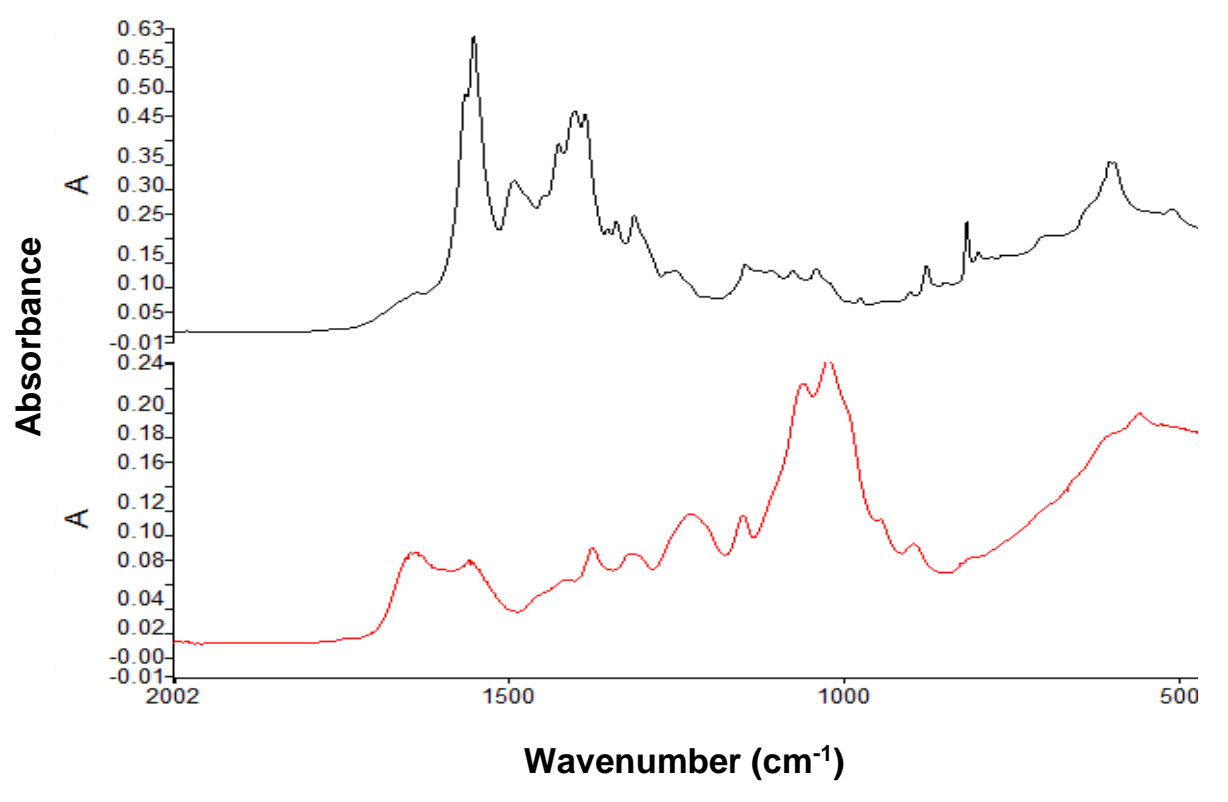

Fig. 3. FTIR of quaternized nano-chitosan oligomers (black) and non-quaternized nano-chitosan oligomers (red)

Characterization of nano-chitosan-TPP and quaternized-nano-chitosan-TPP particles

Based on ionic gelation of chitosan with tripolyphosphate anions, nano-chitosanTPP particles were prepared (Fig. 4). The formation of non-quaternized nano-chitosan oligomers with TPP was stronger than quaternized nano-chitosan oligomers (trimethylchitosan oligomers, TMC) with TPP. The TPP contained $\mathrm{P}_{3} \mathrm{O}_{10}$ ions that neutralized amine ions $\left(\mathrm{NH}_{3}{ }^{+}\right)$in chitosan oligomers (Bhumkar and Pokharkar 2006), but with the TMC process it was more complicated, as TMC had three amine sites, including trimethylated quaternary $\left(\mathrm{N}\left(\mathrm{CH}_{3}\right)_{3}{ }^{+}\right)$, demethylated $\left(\mathrm{N}\left(\mathrm{CH}_{3}\right)_{2} \mathrm{H}^{+}\right)$, monomethylated $\left(\mathrm{N}\left(\mathrm{CH}_{3}\right) \mathrm{H}_{2}^{+}\right)$, and $\left(\mathrm{NH}_{3}{ }^{+}\right)$sites.

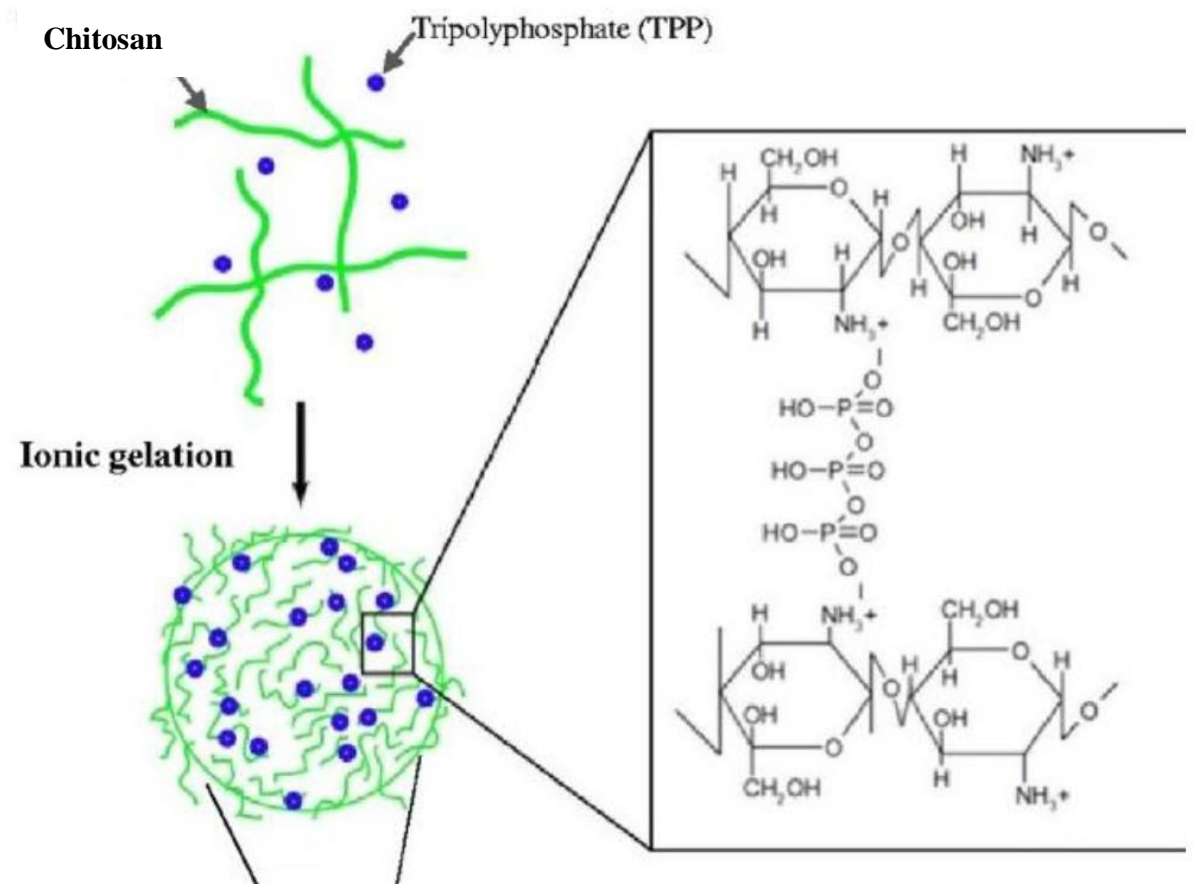

Fig. 4. Ionic gelation of chitosan with tripolyphosphate (TPP) (Ibrahim et al. 2017) 


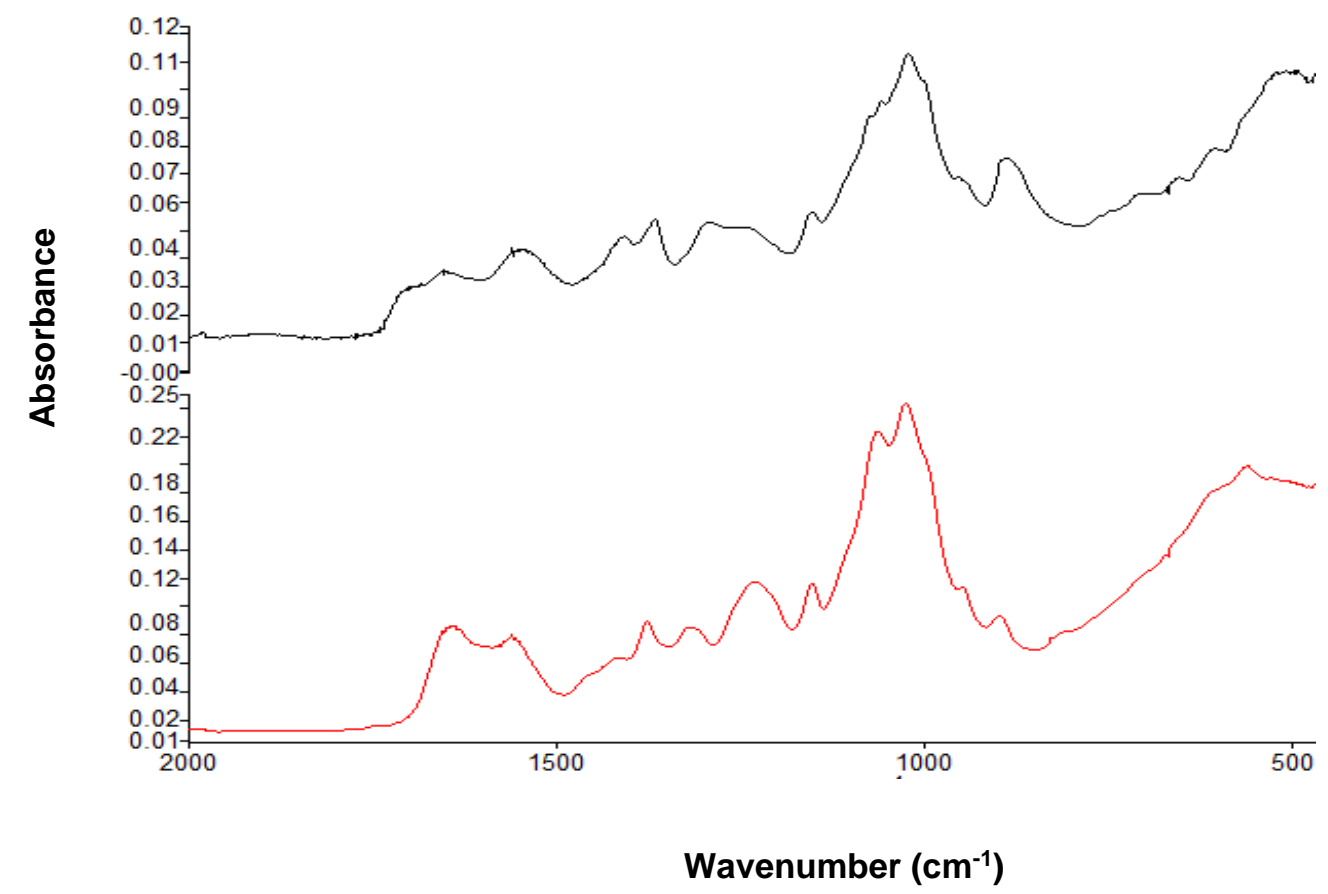

Fig. 5. FTIR of nano-chitosan-TPP particles (black) and nano-chitosan oligomers (red)

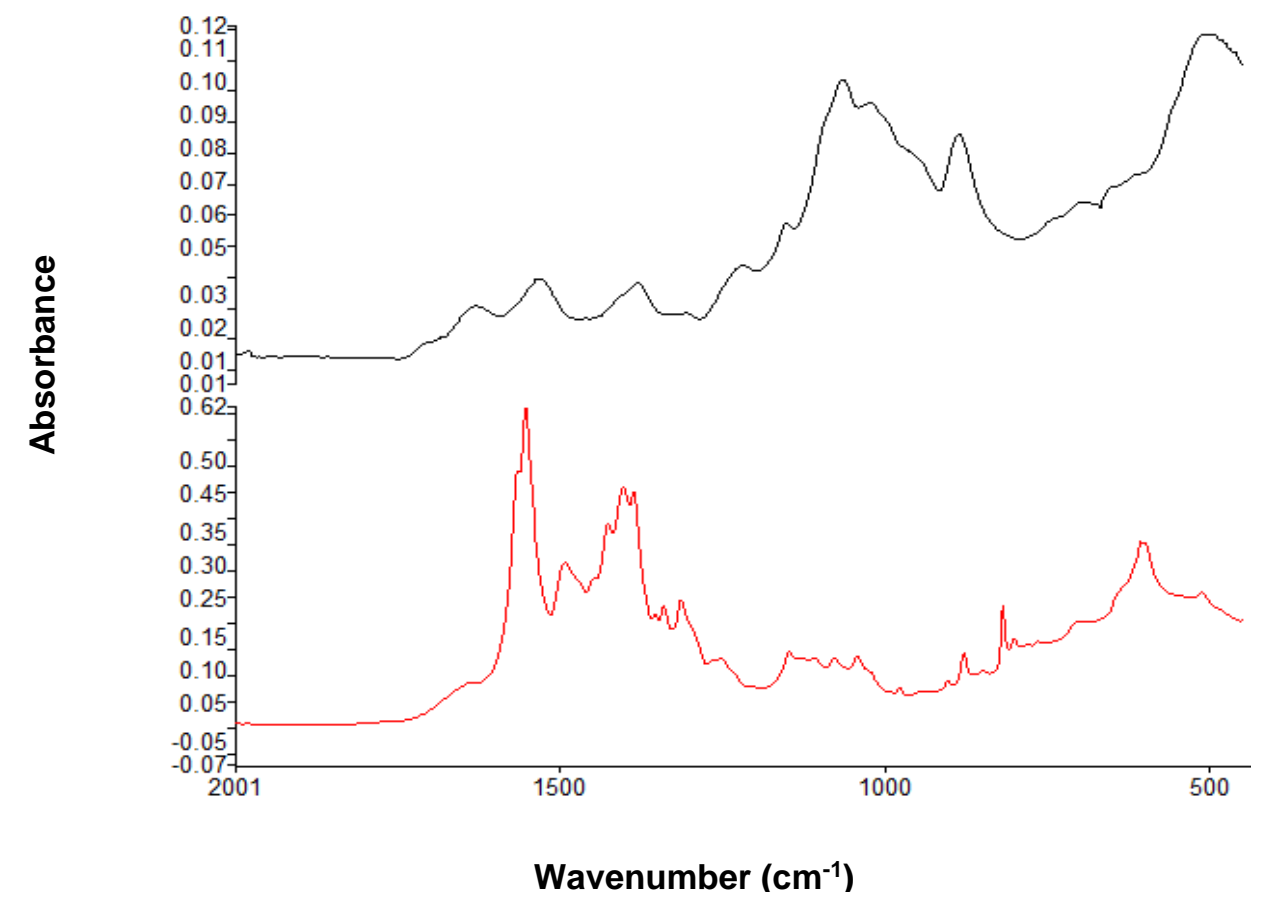

Fig. 6. FTIR of quaternized nano-chitosan-TPP particles (black) and quaternized nano-chitosan (red)

The FTIR spectra for nano-chitosan-TPP particles and quaternized-nano-chitosanTPP particles are illustrated in Figs. 5 and 6, respectively. The FTIR spectra of nanochitosan without TPP and nano-chitosan with TPP (Fig. 5) did not show any major differences. However, there were many differences in the two spectra from quaternized nano-chitosan without TPP and quaternized nano-chitosan with TPP (Fig. 6). The 1234 $\mathrm{cm}^{-1}$ peak indicated an antisymmetric stretch $\left(\mathrm{PO}_{2}\right)$, which indicated that there was likely 
an ionic crosslink between both non-quaternized and quaternized nano-chitosan with TPP. Similar to this study, Lasch et al. (2002) reported that the $1237 \mathrm{~cm}^{-1}$ peak demonstrated an $\mathrm{O}-\mathrm{P}=\mathrm{O}$ antisymmetric stretch $\left(\mathrm{PO}_{2}\right)$. This finding indicated that there was ionic crosslinking between nano-chitosan and TPP (linkage between phosphoric and ammonium ions).

\section{Bulking and Retention}

\section{Mass and volume gain}

The results of mass and volume gain of wood samples treated with vacuum impregnation process in both quaternized and non-quaternized nano-chitosan-TPP particles showed that quaternized nano-chitosan-TPP particles had a higher mass gain compared to control and non-quaternized nano-chitosan-TPP particles. Additionally, treatments 10, 14, and 16 increased mass gain in comparison to treatment 15 (Fig. 7). Treatments 10,11,13,14,16, and 17 resulted in a higher volume gain in comparison to treatments 12, 15, control, and non-quaternized nano-chitosan-TPP particles. Additionally, treatment 15 increased volume gain when compared to treatments 1, 4, 6, 8, and control (Fig. 8).

The contrast analysis revealed that mass gain and volume gain increased in quaternized nano-chitosan-TPP particles in comparison to non-quaternized nano-chitosanTPP particles (Table 3). Additionally, quaternized nano-chitosan-TPP particles increased mass and volume gain relative to control (Table 3). Furthermore, crosslinking of TPP to nano-chitosan resulted in increased mass gain, but not in volume gain, in comparison to nano-chitosan particles without TPP. However, crosslinking of TPP to nano-chitosan particles exhibited higher volume gain compared to control (Table 3).

Mass gain can be expressed as weight percent gain (WPG), which is the increase in mass of wood specimen after treatment with preservatives or retention value. In fact, WPG is used to measure the efficacy of impregnation of preservatives in wood after treatment. Volume gain refers to bulking. According to Rowell (2012), cell wall bulking means that the wood is filled with the chemical when it reaches its green volume. The increased value of both mass and volume after treatment indicated the success of impregnation of nanochitosan particles into the wood cell walls.

The mass and volume gain results indicated that both quaternized chitosan oligomers and quaternized-chitosan-TPP nanoparticles treated samples had more mass and volume gain after treatment in comparison with non-quaternized treated samples. Nowrouzi et al. (2015) used chitosan HMW (MW: $100 \mathrm{kDa}$ to $300 \mathrm{kDa}$ ) to treat fir wood (Abies sp.) via impregnation and then heated wood samples at three different temperatures $\left(60{ }^{\circ} \mathrm{C}, 80^{\circ} \mathrm{C}\right.$, and $\left.100^{\circ} \mathrm{C}\right)$. It has also been reported that chitosan can only increase bulking to a small degree (less than $4 \%$ ) and different temperatures did not influence penetration of chitosan into wood samples (Nowrouzi et al. 2015). In the current research, both quaternized and non-quaternized nano-chitosan-treated samples underwent changes in volume and mass that ranged from $4.9 \%$ to $18 \%$. The LMW chitosan (MW: $50 \mathrm{kDa}$ to 190 $\mathrm{kDa})$ at $1 / 5 \%(\mathrm{v} / \mathrm{v})$ concentration impregnated into radiata pine (Pinus radiata) (Singh et al. 2010). The results of light and SEM demonstrated that chitosan penetrated the cell lumens, small cavities, and cell walls (Singh et al. 2010). Therefore, dimensions of quaternized nano-chitosan particles seemed to be small enough to spread throughout wood elements and penetrate through pits and pores. 


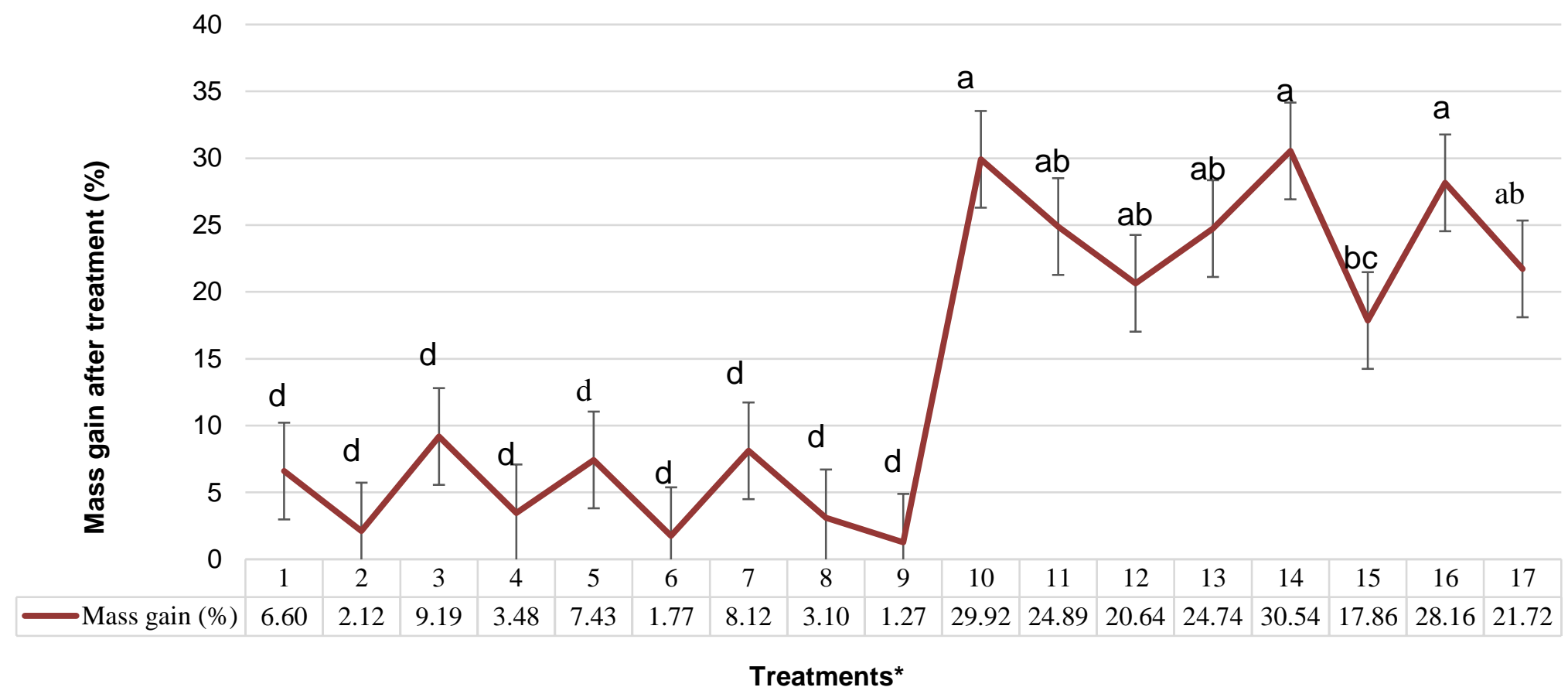

Fig. 7. Percentage of mass gain of wood samples after treating with vacuum impregnation process.

* All 17 treatments are described in Table 2.

a-d Means with no common superscripts differ significantly at $p=0.05$ level 
25

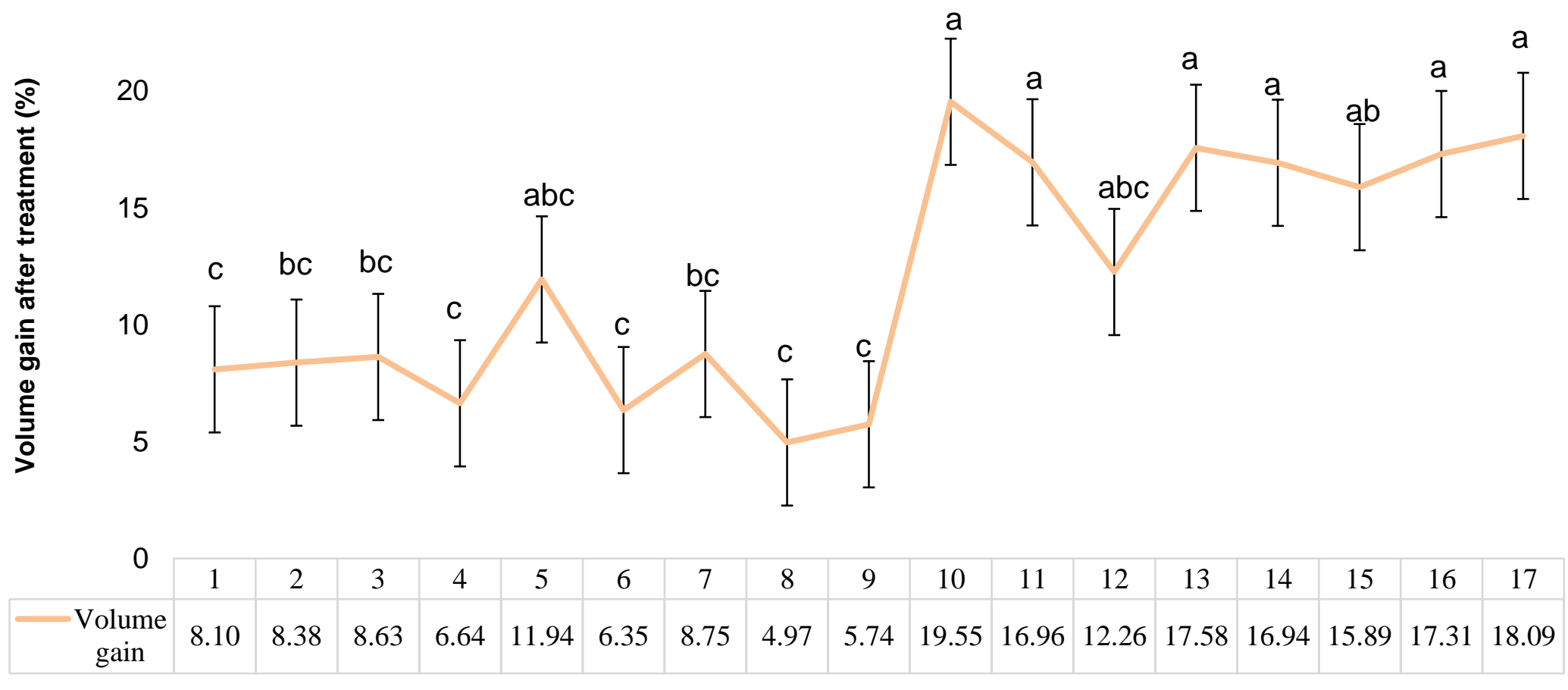

Treatments*

Fig. 8. Percentage of volume gain of wood samples after treating with vacuum impregnation process.

${ }^{*}$ All 17 treatments are described in Table 2.

a-c Means with no common superscripts differ significantly at $p=0.05$ level 
Table 3. Contrast Analysis for Mass Gain, Volume Gain, and Mass Loss

\begin{tabular}{|c|c|c|c|}
\hline Contrasts & $\begin{array}{l}\text { Mass } \\
\text { Gain }\end{array}$ & $\begin{array}{l}\text { Volume } \\
\text { Gain }\end{array}$ & $\begin{array}{l}\text { Mass } \\
\text { Loss }\end{array}$ \\
\hline $\begin{array}{l}\text { Quaternized nano-chitosan-TPP vs. non-quaternized } \\
\text { nano-chitosan-TPP }\end{array}$ & ** & ** & ** \\
\hline Quaternized nano-chitosan-TPP vs. control & ns & * & ns \\
\hline Non-quaternized nano-chitosan-TPP vs. control & ** & ** & ** \\
\hline Nano-chitosan with TPP vs. nano-chitosan without TPP & ** & ** & ns \\
\hline Nano-chitosan with TPP vs. control & ** & ** & * \\
\hline \multicolumn{4}{|c|}{$\begin{array}{l}\text { ns }=\text { not significant. } \\
{ }^{*} \text { Treatment means within the same column within effect with no common superscripts are } \\
\text { significantly different }(P \leq 0.05) \text {. } \\
\text { **Treatment means within the same column within effect with no common superscripts are } \\
\text { significantly different }(P \leq 0.001)\end{array}$} \\
\hline
\end{tabular}

\section{Leaching}

Mass loss

The results of mass loss after leaching of wood samples treated with vacuum impregnation process in both quaternized and non-quaternized nano-chitosan-TPP particles showed that quaternized nano-chitosan-TPP particles had higher mass loss compared to control and non-quaternized nano-chitosan-TPP particles. Additionally, nonquaternized nano-chitosan without TPP had increased mass loss compared to control (Fig. 9). The contrast analysis revealed that mass loss increased in quaternized nano-chitosanTPP particles compared to non-quaternized nano-chitosan-TPP particles. Additionally, crosslinking of TPP to nano-chitosan resulted in increased mass loss (Table 3).

These results indicated that quaternized nano-chitosan particles penetrated the wood but could not fix into cell walls. In contrast, non-quaternized nano-chitosan particles remained in the wood cell walls. Generally, the formation of a strong covalent bond between chitosan and wood had not been previously reported. However, covalent bonds have been found between laccase-oxidized phenols in flax fibers and chitosan (Silva et al. 2011) and between laccase-oxidized phenolic acids and amino groups of chitosan (Aljawish et al. 2012). Fixation of chitosan by acetic anhydride has been reported by Mehrtens (1999). In the cited work the author reported that acetylated chitosan had lower mass loss after leaching, but the possible reason for fixation of chitosan was not described. Potentially, the fixation could be due to acetylation of wood. Treu et al. (2009) used copper in combination with chitosan to make a stronger fixation of chitosan into wood. Posttreatment at a temperature of $85^{\circ} \mathrm{C}$ was used after impregnation. There, the author reported that post-treatment of chitosan-treated wood samples reduced the leaching of glucosamine, which is the main component of chitosan. Additionally, Nowrouzi et al. (2015) investigated the use of PEG (polyethylene glycol) along with chitosan to improve fixation and retention in fir wood specimens. A higher reaction occurred when PEG and heat were applied during the treatment process (Nowrouzi et al. 2015). That information may explain why in this study, although quaternized nano-chitosan particles were positively charged, they could not fix to cell walls and leached out. 
30

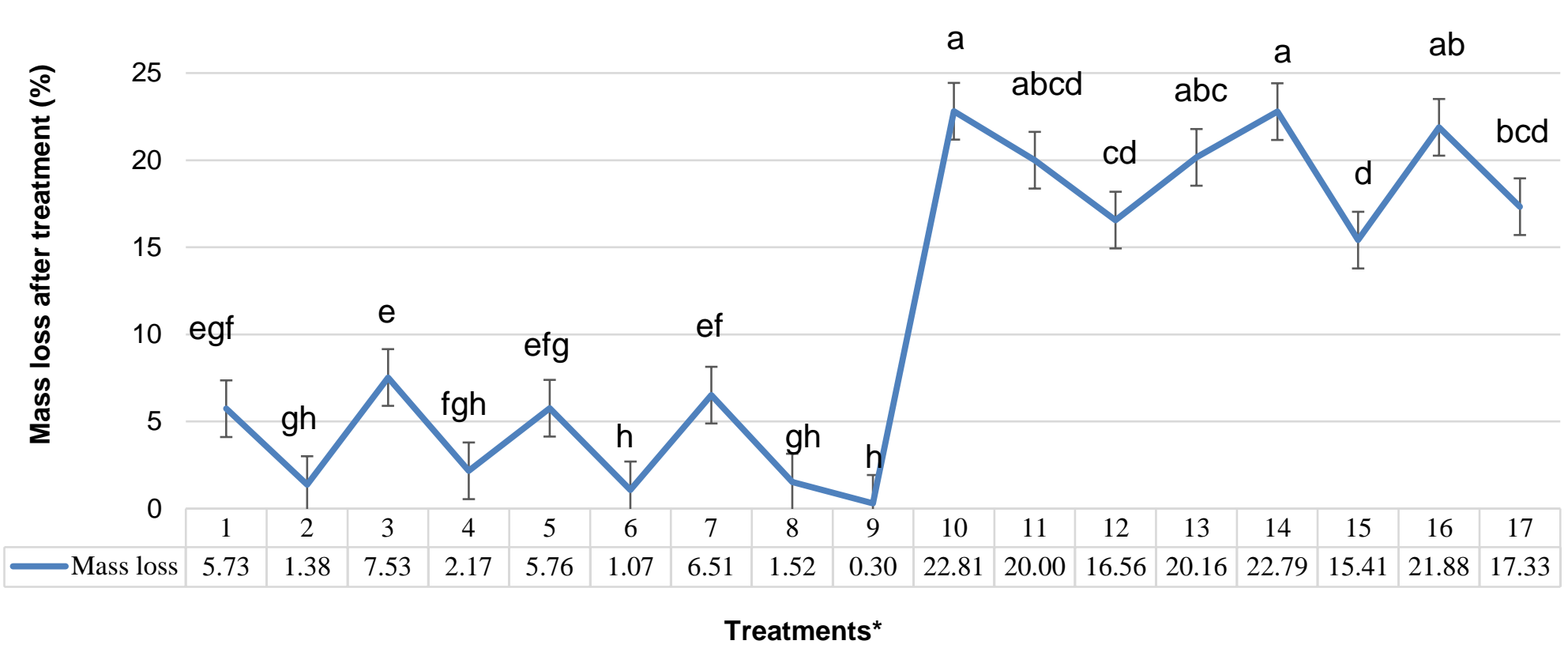

Fig. 9. Percentage of mass loss of leached wood samples

* All 17 treatments are described in Table 2.

a-h Means with no common superscripts differ significantly at $p=0.05$ level 


\section{CONCLUSIONS}

1. Compression strength results showed that hydroquinone (HQ) was the best mediator to be used with laccase for enzymatic modification of wood to increase the reactivity of wood and promote binding of nano-chitosan-TPP particles to wood.

2. Degree of polymerization of four with an applicable amount of sodium nitrite through depolymerization was successfully obtained and the size of chitosan oligomers was confirmed by thin layer chromatography.

3. The methylation of chitosan oligomers through the quaternization process and the formation of nano-chitosan-TPP particles were confirmed by FTIR spectra.

4. The result of bulking and leaching indicated that chitosan nanoparticles effectiveness was obtained in the short time period. It was essential that nano-chitosan particles penetrate and fix into the wood cell walls as well as cell lumens and cavities for longterm protection. These nanoparticles could potentially be used as wood preservatives to treat wood for interior applications. Further research is required to determine the exterior applications of nano-chitosan-TPP particles.

\section{ACKNOWLEDGEMENTS}

This publication is a contribution of the Forest and Wildlife Research Center (FWRC), Mississippi State University. This material is based upon work that is supported by the National Institute of Food and Agriculture and the U.S. Department of Agriculture (No. 2016-67022-25090).

\section{REFERENCES CITED}

Alfredsen, G., Eikenes, M., Militz, H., and Solheim, H. (2004). "Screening of chitosan against wood-deteriorating fungi," Scand. J. Forest Res. 19(5), 4-13. DOI: 10.1080/02827580410017807

Aljawish, A., Chevalot, I., Piffaut, B., Rondeau-Mouro, C., Girardin, M., Jasniewski, J., Scher, J., and Muniglia, L. (2012). "Functionalization of chitosan by laccasecatalyzed oxidation of ferulic acid and ethyl ferulate under heterogeneous reaction conditions," Carbohyd. Polym. 87(1), 537-544. DOI: 10.1016/j.carbpol.2011.08.016

AWPA E11-16 (2016). "Standard method for accelerated evaluation of preservative leaching," American Wood Protection Association, Birmingham, AL, USA.

Bhumkar, D. R., and Pokharkar, V. B. (2006). "Studies on effect of pH on cross-linking of chitosan with sodium tripolyphosphate: A technical note," AAPS PharmSciTech 7(2), E138-E143. DOI: 10.1208/pt070250

Bordenave, N., Grelier, S., and Coma, V. (2008). "Advances on selective C-6 oxidation of chitosan by TEMPO," Biomacromolecules 9(9), 2377-2382. DOI: $10.1021 / \mathrm{bm} 800375 \mathrm{v}$

Cabrera, C. C., and Cutsem, P. V. (2005). "Preparation of chitooligosaccharide with degree of polymerization higher than 6 by acid or enzymatic degradation of chitosan," Biochem. Eng. J. 25(2), 165-172. DOI: 10.1016/j.bej.2005.04.025 
Cha, S. Y., Lee, J. K., Lim, B. M., Lee, T. S., and Park, W. H. (2000). “Conjugated vinyl derivatives of chitooligosaccharide," J. Polym. Sci. 39(6), 880-887.

Chittenden, C., Wakeling, R., and Kreber, B. (2003). "Growth of two selected sap stain fungi and one mould on chitosan amended nutrient medium," in: $34^{\text {th }}$ Annual Meeting of the International Group of Wood Preservation, Brisbane, Australia, 03-10466

Choi, Y. J., Kim. E. J., Piao, Z., Yun, Y. C., and Shin, Y. C. (2004). "Purification and characterization of chitosanase from Bacillus sp. strain KCTC 0377BP and its application for the production of chitosan oligosaccharides," Appl. Environ. Microbiol. 70(8), 4522-4531. DOI: 10.1128/AEM.70.8.4522-4531.2004

Curotto, E., and Aros, F. (1993). "Quantitative determination of chitosan and the percentage of free amino groups," Anal. Biochem. 211(2), 240-243. DOI: 10.1006/abio.1993.1263

De Britto, D., De Moura, M., Aouada, F. A., Mattoso, L., and Assis, O. B. G. (2012). "N,N,N-trimethyl chitosan nanoparticles as a vitamin carrier system," Food Hydrocolloid. 27(2), 487-493. DOI: 10.1016/j.foodhyd.2011.09.002

Eikenes, M., Alfredsen, G., Christensen, B., Militz, H., and Solheim, H. (2005). "Comparison of chitosans with different molecular weights as possible wood preservatives," J. Wood Sci. 51(4), 387-394. DOI: 10.1007/s10086-004-0659-6

Furusaki, E., Ueno, Y., Sakairi, N., Nishi, N., and Tokur, S. (1995). "Facile preparation and inclusion ability of a chitosan derivative bearing carboxymethyl- $B$-cyclodextrin," Carbohydr. Polym. 29(I), 29-34.

Huang, K. S., Sheu, Y. R., and Chao, I. C. (2009). "Preparation and properties of nanochitosan," Polym.-Plast. Technol. Eng. 48(12), 1239-1243.

Hussain, I., Singh, T., and Chittenden, C. (2012). "Preparation of chitosan oligomers and characterization: Their antifungal activities and decay resistance," Holzforschung 66(1), 119-125. DOI: 10.1515/HF.2011.130

Ibrahim, H. M., Ali, E., and Sabry, H. (2017). "Haloperidol-loaded chitosan nanocomposites improve liver and kidney functions and lipid profile of male rats," Res. J. Pharm. Biol. Chem. Sci. 8(3), 1135-1145.

Ikono, R., Vibriani, A., Wibowo, I., Saputro, K. E., Muliawan, W., Bachtiar, B. M., Mardliyati, E., Bachtiar, E. W., Rochman, N. T., Kagami, H., Xianqi, L., NagamuraInoue, T., and Tojo, A. (2019). "Nanochitosan antimicrobial activity against Streptococcus mutans and Candida albicans dual-species biofilms," BMC Res Notes 12(1), article no. 383. DOI: 10.1186/s13104-019-4422-x.

Junior, E. N. D. O (2016). "Fungal growth control by chitosan and derivatives," in: Fungal Pathogenicity, S. Sultan (ed.), Ouro Branco, Brazil, pp. 61-81. DOI: $10.5772 / 60789$.

Kumar, M. (2000). "A review of chitin and chitosan applications," React. Funct. Polym. 46(1), 1-27. DOI: 10.1016/S1381-5148(00)00038-9

Kumar, N., Kaur, P., and Surekha, B. (2017). "Advances in bio-nanocomposite materials for food packaging: A review," Nutrition \& Food Science 47(4), 591-606. DOI: 10.1108/NFS-11-2016-0176

Larnøy, E., Dantz, S., Eikenes, M., and Militz, H. (2006a). "Screening of properties of modified chitosan-treated wood," Wood Mater. Sci. Eng. 1(2), 59-68. DOI: 10.1080/17480270600861118

Larnøy, E., Eikenes, M., and Militz, H. (2006b). "Evaluation of factors that have an influence on the fixation of chitosan in wood," Wood Mater. Sci. Eng. 1(3-4), 138- 
145. DOI: $10.1080 / 17480270701200562$

Lasch, P., Boese, M., Pacifico, A., and Diem, M. (2002). "FT-IR spectroscopic investigations of single cells on the subcellular level," Vib. Spectrosc. 28(1), 147-157. DOI: 10.1016/S0924-2031(01)00153-9

Mansur, H., Manur, A. A. P., Curti, E., and Almeida, M. V. (2013). "Functionalizedchitosan/quantum dot nano-hybrids for nanomedicine applications: Towards biolabeling and biosorbing phosphate metabolites," J. Mater. Chem. B 1(12), 16961711. DOI: 10.1039/C3TB00498H

Mehrtens, S. (1999). Untersuchungen zur Schutzwirkung von Chitosan gegenüber Holzpilzen [Protective Effect of Chitosan Against Wood Fungi], Diploma Thesis, Fachbereich Biologie, University of Hamburg, Hamburg, Germany (In German)

Morozova, O. V., Shumakovich, G. P., Shleev, S. V., and Yaropolov, Y. I. (2007). "Laccase-mediator systems and their applications: A review," Appl. Biochem. Microbiol. 43(5), 523-535. DOI: 10.1134/S0003683807050055

Nowrouzi, Z., Mohebby, B., and Younesi, H. (2015). "Treatment of fir wood with chitosan and polyethylene glycol," J. Forestry Res. 27(4), 959-966. DOI: 10.1007/s11676-015-0174-1

Ozdemir, F., Ayrilmis, N., Kaymakci, A., and Kwon, J. (2014). "Improving dimensional stability of injection molded wood plastic composites using cold and hot water extraction methods," Maderas. Cienc. Tecnol. 16(3), 365-372. DOI: 10.4067/S0718221X2014005000029

Rowell, R. (2012). "Chemical modification of wood to produce stable and durable composites," Cell. Chem. Technol. 46(7-8), 443-448.

Seong, H.-S., Kim, J.-P., and Ko, S.-W. (1999). "Preparing chito-oligosaccharides as antimicrobial agents for cotton," Text. Res. J. 69(7), 483-488. DOI: 10.1177/004051759906900704

Silva, C., Matamá, T., Kim, S., Padrão, J., Prasetyo, E. N., Kudanga, T., Nyanhongo, G. S., Guebitz, G. M., Casal, M., and Cavao-Paulo, A. (2011). "Antimicrobial and antioxidant linen via laccase-assisted grafting," React. Funct. Polym. 71(7), 713-720. DOI: 10.1016/j.reactfunctpolym.2011.03.011

Singh, A. P., Singh, T., and Rickard, C. L. (2010). "Visualizing impregnated chitosan in Pinus radiata early wood cells using light and scanning electron microscopy," Micron 41(3), 263-267. DOI: 10.1016/j.micron.2009.11.006

Treu, A., Larnøy, E., and Militz, H. (2009). "Leaching of new environmental friendly wood protection agents," in: Proceedings of the 5th meeting of the Nordic-Baltic Network in Wood Material Science and Engineering (WSE), Copenhagen, Denmark, pp. 33-40.

Xu, T., Xin, M., Li, M., Huang, H., and Zhou, S. (2010). "Synthesis, characteristic and antibacterial activity of $N, N, N$-trimethyl chitosan and its carboxymethyl derivatives," Carbohyd. Polym. 81(4), 931-936. DOI: 10.1016/j.carbpol.2010.04.008

Xu, Y., Du, Y., Huang, R., and Gao, L. (2003). "Preparation and modification of N-(2hydroxyl) propyl-3-trimethyl ammonium chitosan chloride nanoparticle as a protein carrier," J. Biomater. 24(27), 5015-5022.

Article submitted: Nov. 26, 2019; Peer review completed: Feb. 29, 2020; Revised version received: March 4, 2020; Accepted: March 5, 2020; Published: March 6, 2020

DOI: $10.15376 /$ biores.15.2.2800-2817 